\title{
Lipoteichoic Acid Isolated from Staphylococcus aureus Induces Both Epithelial-Mesenchymal Transition and Wound Healing in HaCaT Cells
}

\author{
Seongjae Kim ${ }^{1}$, Hyeoung-Eun Kim ${ }^{1}$, Boyeon Kang ${ }^{1}$, Youn-Woo Lee ${ }^{1}$, Hangeun Kim ${ }^{1,2 *}$, and Dae Kyun Chung ${ }^{1,23 *}$ \\ ${ }^{1}$ Graduate School of Biotechnology and Institute of Life Science and Resources, Kyung Hee University, Yongin 17104, Republic of Korea \\ ${ }^{2}$ Skin Biotechnology Center, Kyung Hee University, Yongin 17104, Republic of Korea \\ ${ }^{3}$ RNA Inc., College of Life Science, Kyung Hee University, Yongin 17104, Republic of Korea
}

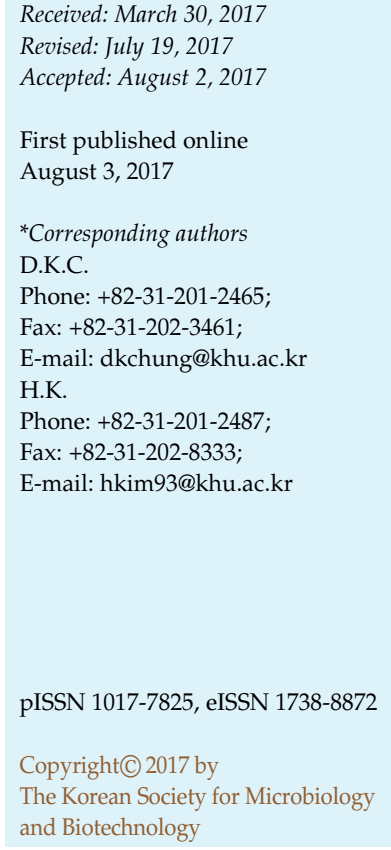

Lipoteichoic acid (LTA), a cell wall component of gram-positive bacteria, is recognized by Toll-like receptor 2, expressed on certain mammalian cell surfaces, initiating signaling cascades that include nuclear factor kappa-light-chain-enhancer of activated B cells (NF- $\mathrm{B}$ ) and mitogen-activated protein kinase. There are many structural and functional varieties of LTA, which vary according to the different species of gram-positive bacteria that produce them. In this study, we examined whether LTA isolated from Staphylococcus aureus (aLTA) affects the expression of junction proteins in keratinocytes. In HaCaT cells, tight junctionrelated gene expression was not affected by aLTA, whereas adherens junction-related gene expression was modified. High doses of aLTA induced the phosphorylation of extracellular signal-regulated protein kinases 1 and 2, which in turn induced the epithelial-mesenchymal transition (EMT) of HaCaT cells. When cells were given a low dose of aLTA, however, NF-kB was activated and the total cell population increased. Taken together, our study suggests that LTA from S. aureus infections in the skin may contribute both to the outbreak of EMTmediated carcinogenesis and to the genesis of wound healing in a dose-dependent manner.

Keywords: Lipoteichoic acid, Staphylococcus aureus, epithelial-mesenchymal transition, keratinocytes, Toll-like receptor, wound healing

\section{Introduction}

Staphylococcus aureus is a gram-positive bacterium frequently found on skin. When pathogenic, it can cause various skin diseases such as cellulitis, folliculitis, impetigo scald skin syndrome, and atopic dermatitis. Skin diseases can occur as a result of exogenous factors, as well as environmental changes or changes in the ratio of $S$. aureus to other microflora on the skin [1, 2]. In general, lipoteichoic acid (LTA) from gram-positive bacteria activates a wide variety of signaling cascades, including those involving nuclear factor kappa-light-chain-enhancer of activated B cells (NF- $\kappa \mathrm{B}$ ) and mitogen-activated protein kinase (MAPK), through interaction with Toll-like receptor (TLR) 2, which results in the induction of pro-inflammatory cytokine secretion. However, different strains and species of grampositive bacteria have their own distinct LTA isomers with varying structures, which leads to diverse physiological effects against mammalian immune cells $[3,4]$.

Cell junctions, such as tight junctions, adherens junctions, and gap junctions, bind epithelial cells to each other, building up the paracellular barrier and controlling paracellular transport and communication between neighboring cells [5]. Claudins are a typical family of proteins that comprise tight junctions, whereas E-cadherin and connexins are the main constituents of adherens junctions and gap junctions, respectively. The variation in the expression pattern of Ecadherin acts as an epithelium-mesenchymal transition (EMT) marker. Cells with an epithelial phenotype normally secrete high levels of E-cadherin, but this expression is 
decreased during EMT. On the other hand, cells with a mesenchymal phenotype express N-cadherin and Snail [6]. In vertebrates, tight junctions are also known as occluding junctions. They join the membranes of neighboring cells to form a virtually impermeable barrier, which serves to maintain the osmotic balance of the cells. Adherens junctions are an intermediate junction, which serve as a bridge connecting the actin cytoskeleton of two cells. Gap junctions are also called communicating junctions, since they directly connect the cytoplasm of two neighboring cells. Through this regulated molecular gate, electrical impulses, various molecules, and ions can move directly between the two cells without contacting the extracellular space. Changes in adherens junctions induce an EMT, which leads to stem cell migration, differentiation, and tumor cell genesis [7, 8]. It has been reported that peptidoglycan (PGN), but not LTA, from $S$. aureus can modulate tight junctions [9]. In the current study, we examined whether aLTA isolated from S. aureus could induce changes in adherens junctions in HaCaT cells. We showed that a low dose of aLTA induced cell proliferation, whereas a high dose of aLTA induced EMT via changes in adherens junctions, which might lead to the generation of skin tumors.

\section{Materials and Methods}

\section{S. aureus Culture}

Brain heart infusion (BHI) broth was used to amplify S. aureus. Briefly, stock cells were inoculated in $5 \mathrm{ml}$ of BHI broth and incubated overnight at $37^{\circ} \mathrm{C}$. Then, $50 \mu \mathrm{l}$ of cultured cells was subcultured in $5 \mathrm{ml}$ of fresh BHI broth and incubated for $18 \mathrm{~h}$ at $37^{\circ} \mathrm{C}$. Next, $5 \mathrm{ml}$ of cultured cells was transferred to $500 \mathrm{ml}$ of fresh BHI broth and further incubated for $18 \mathrm{~h}$ at $37^{\circ} \mathrm{C}$. Finally, $500 \mathrm{ml}$ of cultured cells was transferred to $8 \mathrm{~L}$ of $\mathrm{BHI}$ broth and incubated for $16 \mathrm{~h}$ at $37^{\circ} \mathrm{C}$.

\section{Purification of aLTA}

S. aureus was harvested from the $8 \mathrm{~L}$ culture by centrifugation $\left(4,000 \times g, 4^{\circ} \mathrm{C}\right)$ and washed three times with distilled water (DW). After centrifugation, the pellet was resuspended in $0.1 \mathrm{M}$ sodium citrate buffer ( $\mathrm{pH} 4.7$ ), and then cells were disrupted by sonication. An equal volume of $n$-butanol was added to the $S$. aureus lysates, and the solution was mixed using a magnetic stirrer for $40 \mathrm{~min}$. After centrifugation at 13,000 $\times g$ for $20 \mathrm{~min}$, the aqueous phase was collected. The aqueous phase containing LTA was dialyzed with DW, and LTA was purified using octyl-Sepharose chromatography. Potential contamination of the isolated LTA was assessed by silver staining for protein contamination and a Limulus amebocyte lysate test for endotoxin contamination (GenScript, USA). Contamination with nucleic acids was examined by measuring the ratio of absorbance at 260 and $280 \mathrm{~nm}$.

\section{Mammalian Cell Culture and Proliferation Assay}

The human keratinocyte cell line HaCaT was maintained in Dulbeco's modified Eagle's medium supplemented with 10\% heat-inactivated fetal bovine serum, $100 \mathrm{U} / \mathrm{ml}$ penicillin, and $100 \mu \mathrm{g} / \mathrm{ml}$ streptomycin at $37^{\circ} \mathrm{C}$ in a humidified $5 \% \mathrm{CO}_{2}$ incubator. For the cell viability assay, HaCaT cells were seeded into 96-well plates, and different doses of aLTA were added to each well. Cells were stimulated for 3 days, and cell viability was determined using a PreMix WST-1 Cell Proliferation Assay System (Takara, Japan). Absorbance was measured using a microplate reader (Eppendorf BioPhotometer, USA) at a test wavelength of $450 \mathrm{~nm}$ and reference wavelength of $600 \mathrm{~nm}$.

\section{Real-Time PCR}

cDNA was synthesized with total RNA isolated from HaCaT cells treated with aLTA. For total RNA isolation, TRIzol reagent (Takara) was used according to the manufacturer's instructions. An iScript cDNA synthesis kit (Bio-Rad, USA) was used for cDNA synthesis. To determine the expression level of target mRNA, a CFX Connect Real-Time PCR Detection System (Bio-Rad) with a SYBR Ex Taq II master mix (Takara) was used. The following sequences were used for forward and reverse primers: 5'ATGCTGATGCCCCCAATACC- $3^{\prime}$ and 5'-GCTGTGAGGATG CCAGTTTC-3' for E-cadherin; 5'-TGACAATGACCCCACAGCTC$3^{\prime}$ and $5^{\prime}$-GTCCTGCTCACCACCACTAC-3' for N-cadherin; 5'CGAGTGGTTCTTCTGCGCTA- $3^{\prime}$ and $5^{\prime}$-TGCAGCTCGCTGTAG TTAGG-3' for Snail; and 5'-GTCTTCACCACCATGGAGAA-3' and 5'-AGGAGGCATTGCTGATGATC-3' for GAPDH. To inhibit the appropriate signaling pathways, cells were treated with NF$\kappa \mathrm{KB}(\# 481406)$ and extracellular signal-regulated protein kinase (ERK) (\#328006) inhibitors (Merck, Kenilworth, USA) followed by aLTA. mRNA expression was examined by real-time PCR. Gene expression was normalized to GAPDH.

\section{Western Blot Analysis}

aLTA-treated HaCaT cells were lysed with $2 \times$ Laemmli sample buffer. After boiling at $100^{\circ} \mathrm{C}$ for $5 \mathrm{~min}$, proteins were separated by sodium dodecyl sulfate-polyacrylamide gel electrophoresis on an $8-12 \%$ gel and transferred onto a polyvinylidene fluoride membrane. Then, $5 \%$ skim milk dissolved in TBS-T (20 mM Tris$\mathrm{HCl}, 150 \mathrm{mM} \mathrm{NaCl}, 0.05 \%$ Tween 20) was used as the blocking solution. The primary antibodies for phospho-ERK1/2, phosphoNFкB-p65, phospho-SAPK/JNK, phospho-p38, phospho-cAMP response element binding protein (CREB) (Cell Signaling Technology, USA), E-cadherin, N-cadherin, and $\beta$-actin HRP (Santa Cruz, USA) were diluted in TBS-T and incubated with the membranes overnight at $4^{\circ} \mathrm{C}$. HRP-conjugated secondary antibodies for mouse or rabbit (Santa Cruz) were diluted in TBS-T and incubated with the membranes for $1 \mathrm{~h}$ at room temperature. Protein bands were detected by enhanced chemiluminescence reagent and with $\beta$-actin as a loading control.

\section{Wound Healing Assay}

HaCaT cells were seeded into a 6-well plate at approximately 
$80 \%$ confluency. When cells were $100 \%$ confluent, a wound in the culture was made using a pipette tip. After washing to remove debris and the culture medium, fresh medium was added to the culture. Before stimulation with aLTA, a phase-contrast microscopic image of the cells was taken. Another picture was taken after $24 \mathrm{~h}$ of stimulation with aLTA. The healed area was calculated using Image J software.

\section{Statistical Analysis}

The data are shown as the means \pm SDs of at least three experiments. Differences were considered statistically significant when the $p$-value was $<0.05$.

\section{Results}

High Doses of aLTA Promoted Phenotypic Changes of HaCaT Cells into Mesenchymal-Like Cells

Similarly to other cell wall components, such as PGN, teichoic acid, and lipopolysaccharide, aLTA induces proinflammatory cytokine production from macrophages and also has cytotoxic activity [10]. To examine the cytotoxicity of aLTA in HaCaT cells, cells were treated with varying doses of aLTA for 24,48 , and $72 \mathrm{~h}$, and cell viability was examined with a WST-1 cell proliferation assay. The population of $\mathrm{HaCaT}$ cells treated with 1 and $10 \mu \mathrm{g} / \mathrm{ml}$ of aLTA increased and survived until $72 \mathrm{~h}$. On the other hand, $100 \mu \mathrm{g} / \mathrm{ml}$ of aLTA decreased the cell population when compared with controls, indicating that the high dose of aLTA induced cell death after $48 \mathrm{~h}$ of treatment (Fig. 1A).
In addition, aLTA treatment increased phenotypic changes in HaCaT cells in an aLTA dose dependent manner. As shown in Fig. 1B, some of the cells stimulated by aLTA showed a mesenchymal phenotype, suggesting that aLTA induced EMT in HaCaT cells.

\section{High Doses of aLTA Upregulated Mesenchymal Phenotype Markers in HaCaT Cells}

The downregulation of E-cadherin in epithelial cells is considered to be a primary event in EMT. On the other hand, the expression of $\mathrm{N}$-cadherin and Snail-1 is increased when the transition is complete [6]. In the current study, when $\mathrm{HaCaT}$ cells were treated with $1 \mu \mathrm{g} / \mathrm{ml}$ of aLTA, the mRNA level of E-cadherin was increased up to 30-fold compared with controls after $12 \mathrm{~h}$ of stimulation. This mRNA level was decreased by 3.2-fold in cells treated with $10 \mu \mathrm{g} / \mathrm{ml}$ aLTA. Interestingly, E-cadherin mRNA expression levels decreased over $50 \%$ in cells treated with $100 \mu \mathrm{g} / \mathrm{ml}$ of aLTA compared with untreated cells (Fig. 2A). On the other hand, the mRNA levels of N-cadherin and Snail-1 were unchanged and both decreased about 50\% after treatment with $1 \mu \mathrm{g} / \mathrm{ml}$ of aLTA. Importantly, mRNA levels of N-cadherin and Snail-1 increased 1.5- and 4-fold, respectively, after treatment with a dose higher than $10 \mu \mathrm{g} / \mathrm{ml}$ of aLTA. When cells were treated with $100 \mu \mathrm{g} / \mathrm{ml}$ of aLTA, the mRNA levels of both $\mathrm{N}$-cadherin and Snail-1 were increased by about 8 -fold (Fig. 2B). By contrast, the protein level of E-cadherin was increased $3 \mathrm{~h}$ after $1 \mu \mathrm{g} / \mathrm{ml}$ of
A

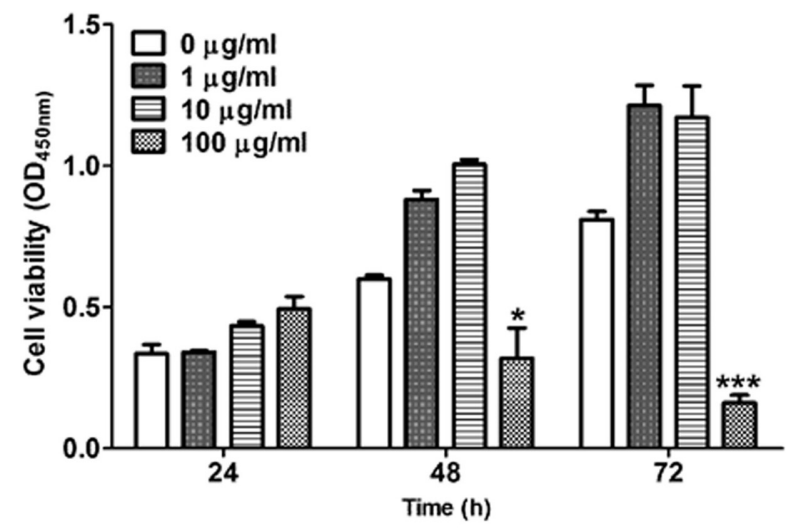

B $0 \mu \mathrm{g} / \mathrm{ml}$
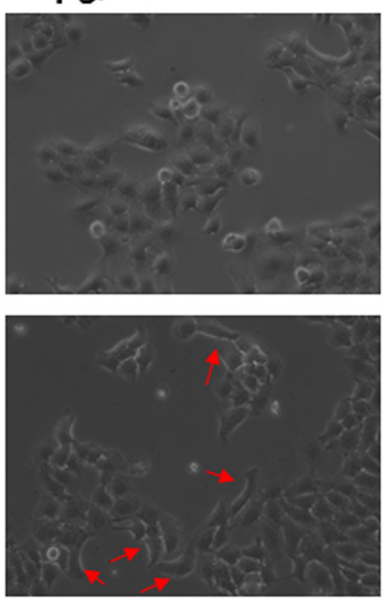

$10 \mu \mathrm{g} / \mathrm{ml}$
$1 \mu \mathrm{g} / \mathrm{ml}$
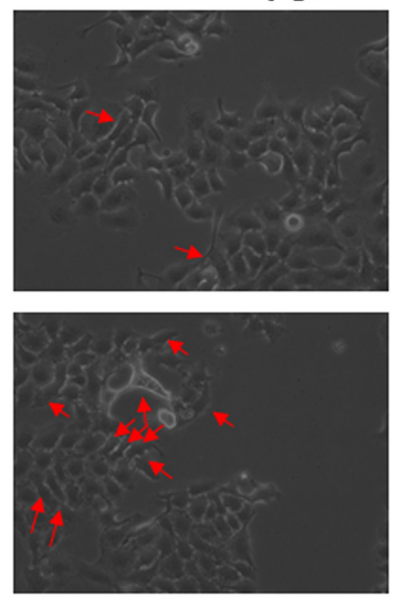

$100 \mu \mathrm{g} / \mathrm{ml}$

Fig. 1. aLTA differentially affects HaCaT cell viability.

(A) HaCaT cells were treated with aLTA at the indicated concentrations and times in 96-well plates. Cell viability was assessed with WST-1 reagent. (B) Morphological changes in HaCaT cells treated with 0, 1, 10, and $100 \mu \mathrm{g} / \mathrm{ml}$ aLTA were observed under a microscope. Data are presented as the mean $\pm \mathrm{SD} ;{ }^{*} p<0.05,{ }^{* * *} p<0.001$ compared with untreated cells. Red arrows indicate cells having mesenchymal phenotype. 
A

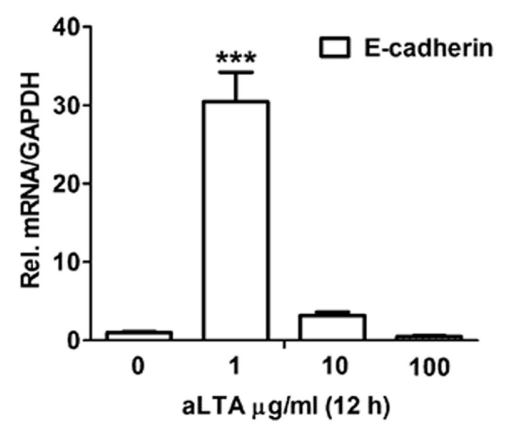

D

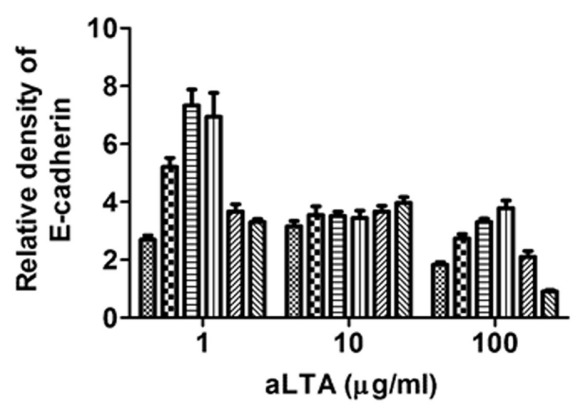

B

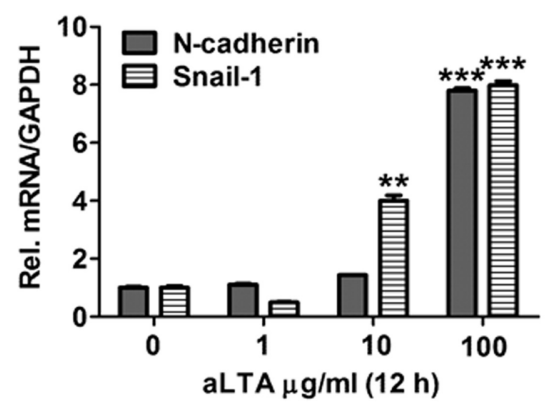

$\mathbf{E}$
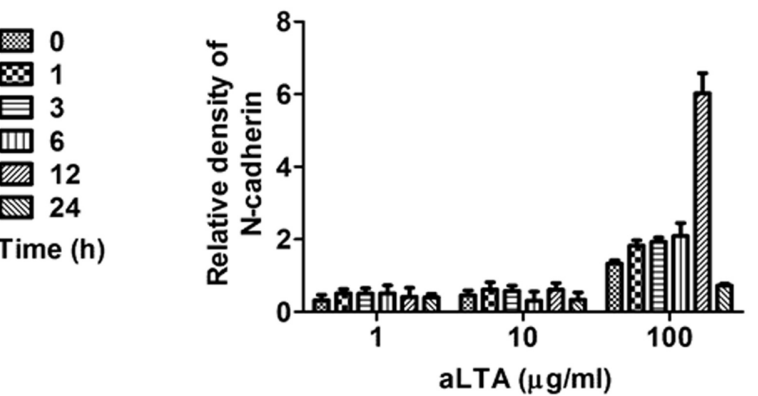

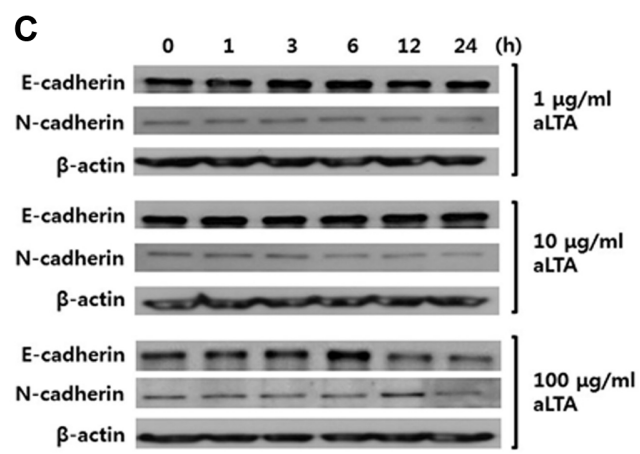

Fig. 2. aLTA regulated mesenchymal phenotype marker expression.

(A) E-Cadherin mRNA expression was increased in HaCaT cells treated with $1 \mu \mathrm{g} / \mathrm{ml}$ aLTA for $12 \mathrm{~h}$. (B) N-Cadherin and Snail-1 mRNA expression was increased after treatment with both 10 and $100 \mu \mathrm{g} / \mathrm{ml}$ aLTA. (C) E-Cadherin and $\mathrm{N}$-cadherin protein expression levels were examined by western blot after aLTA treatment. Densitometry analysis for E-cadherin (D) and N-cadherin (E) protein band intensities was done by ImageJ software after repeated experiments. Data are presented as the mean $\pm \mathrm{SD} ;{ }^{* *} p<0.01,{ }^{* * *} p<0.001$ compared with untreated cells.

aLTA treatment, and this expression was maintained up to $24 \mathrm{~h}$ after treatment. However, E-cadherin in cells treated with $100 \mu \mathrm{g} / \mathrm{ml}$ aLTA was decreased at the protein level after $12 \mathrm{~h}$ of stimulation. On the other hand, the $\mathrm{N}$-cadherin protein level was upregulated by $100 \mu \mathrm{g} / \mathrm{ml}$ of aLTA at $12 \mathrm{~h}$, whereas expression of this protein was not increased in cells stimulated with 1 or $10 \mu \mathrm{g} / \mathrm{ml}$ aLTA (Fig. 2C). The densitometry results for E-cadherin (Fig. 2D) and N-cadherin (Fig. 2E) was added. These results indicated that a low dose of aLTA increased E-cadherin expression, whereas a high dose of aLTA increased N-cadherin and Snail-1 expression. This gene expression pattern is a hallmark of EMT, and evidence of the mesenchymal transition of the $\mathrm{HaCaT}$ cells treated with high doses of aLTA.

EMT in HaCaT Cells Treated with a High Dose of aLTA Was Mediated by the Inactivation of NF- $\kappa B$ and by the Activation of ERK1/2

To examine the effect of diverse doses of aLTA on the TLR-mediated signaling pathway, the expression levels of certain MAPKs, such as ERK1/2, JNK1/2, and p38, Akt, and transcription factors, such as CREB and NF- $\kappa \mathrm{B}$, were examined. When cells were stimulated with $1 \mu \mathrm{g} / \mathrm{ml}$ of aLTA, phosphorylation of the NF- $\mathrm{B}$ p65 subunit was increased (Fig. 3A, left panel). This activation of NF- $\kappa B$ was not shown in the cells stimulated with 10 and $100 \mu \mathrm{g} / \mathrm{ml}$ aLTA. Instead, both 10 and $100 \mu \mathrm{g} / \mathrm{ml}$ aLTA increased the phosphorylation of ERK1/2 (Fig. 3A, middle and right panels). The activation of ERK1/2 was not shown in $1 \mu \mathrm{g} / \mathrm{ml}$ aLTA-treated cells. From these results, we postulated that E-cadherin was upregulated by NF- $\mathrm{B}$, which was itself activated by $1 \mu \mathrm{g} / \mathrm{ml}$ aLTA, whereas $\mathrm{N}$-cadherin and Snail-1 were upregulated by ERK1/2, which were activated by 10 or $100 \mu \mathrm{g} / \mathrm{ml}$ aLTA. The activation of JNK, Akt, and CREB was not altered significantly in the time points that we examined. To confirm the role of NF- $\mathrm{BB}$ and ERK1/2 in adherens junction-related gene expression, cells were treated with either an NF-אB or ERK1/2 inhibitor, followed by treatment with aLTA. As we expected, the upregulation of E-cadherin seen in $1 \mu \mathrm{g} / \mathrm{ml}$ aLTA-treated cells was inhibited by the NF- $\mathrm{BB}$ inhibitor, whereas $\mathrm{N}$-cadherin and Snail-1 expression levels were inhibited by the ERK1/2 
A

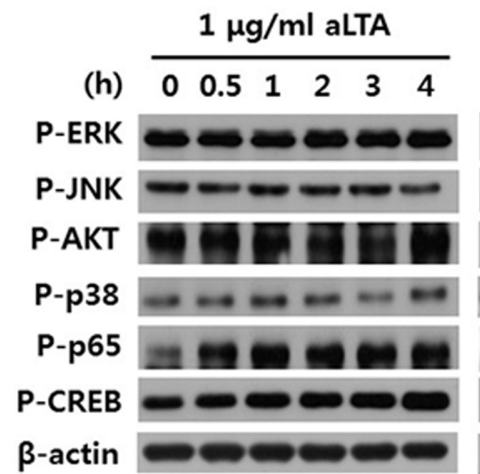

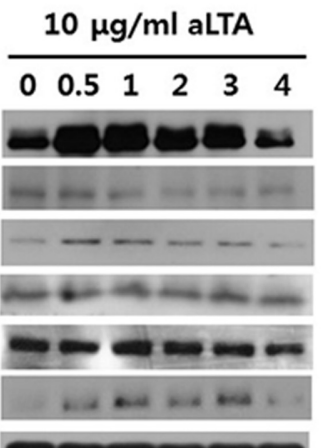

(2)
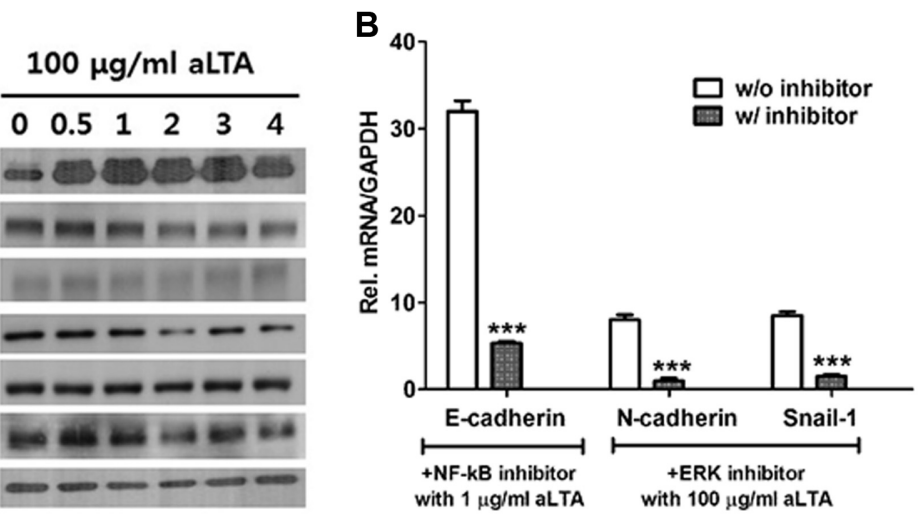

Fig. 3. NF-KB and ERK1/2 activation was induced by aLTA.

(A) $\mathrm{HaCaT}$ cells were treated with aLTA at the indicated concentrations and times, and then the activation of several signaling molecules was examined by western blot analysis. (B) The mRNA expression of mesenchymal markers was examined by real-time PCR after treatment with inhibitors followed by treatment with either 1 or $100 \mu \mathrm{g} / \mathrm{ml}$ aLTA. Data are presented as the mean $\pm \mathrm{SD}$; ${ }^{* * *} p<0.001$ compared with untreated cells.

inhibitor (Fig. 3B), suggesting that adherens junction-related gene expression is differentially regulated by low or high doses of aLTA. Taken together, these results suggested that EMT seen in the $100 \mu \mathrm{g} / \mathrm{ml}$ aLTA-treated cells was mediated by the combined inactivation of NF- $\kappa \mathrm{B}$ and activation of ERK1/2.

\section{Low Dose of aLTA Induced the Proliferation of HaCaT Cells}

In Fig. 1A, we show that a low dose of aLTA induced cell proliferation in a time-dependent manner. The proliferation of aLTA-treated HaCaT cells was assessed using a wound healing assay. Images were taken just after the wound was made, and after $24 \mathrm{~h}$ of aLTA treatment. When HaCaT cells were treated with $1 \mu \mathrm{g} / \mathrm{ml}$ of aLTA, the rate of wound healing was increased when compared with untreated cells. A similar healing rate was shown in cells treated with $10 \mu \mathrm{g} / \mathrm{ml}$ of aLTA . However, when cells were stimulated with $100 \mu \mathrm{g} / \mathrm{ml}$ of aLTA, the rate of healing was lower than that of the control cells (Fig. 4A). ImageJ software was used to calculate the healing rate (Fig. 4B). These results suggested that a low dose of aLTA induced HaCaT cell proliferation, which resulted in wound healing.

\section{Discussion}

Immune cells secrete pro- or anti-inflammatory cytokines through the TLR-mediated signaling pathway when they encounter bacteria. TLR-mediated cytokine production regulates both innate and adaptive immunities. It is well
A

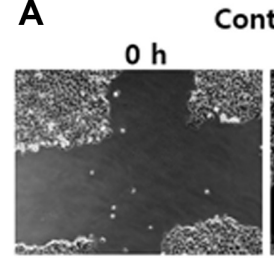

Control

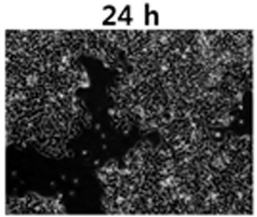

$10 \mu \mathrm{g} / \mathrm{ml}$ aLTA

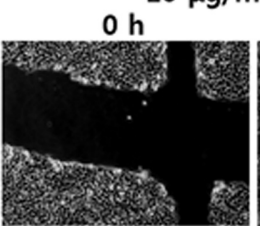
$24 \mathrm{~h}$

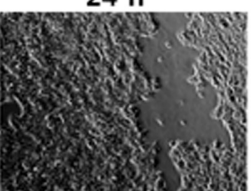

$1 \mu \mathrm{g} / \mathrm{ml}$ aLTA
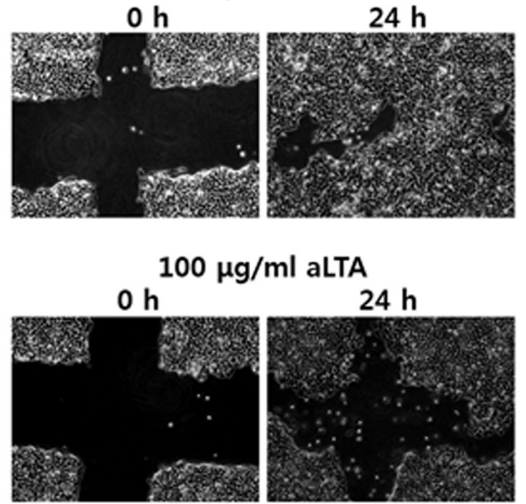

B

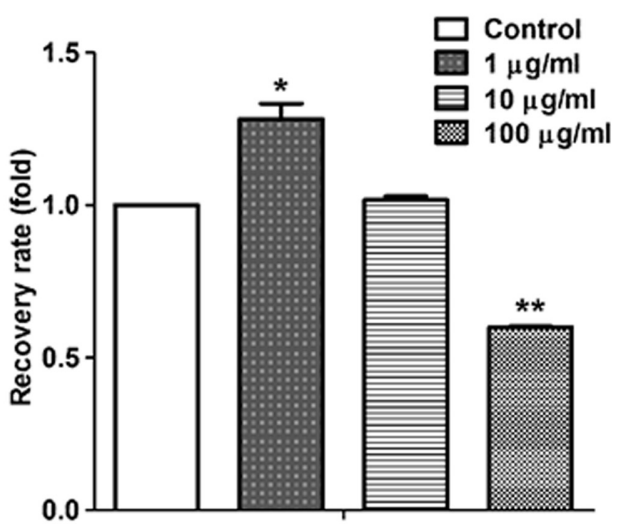

Fig. 4. Low-dose aLTA induced proliferative activity of HaCaT cells.

(A) $\mathrm{HaCaT}$ cells were treated with various doses of aLTA for $24 \mathrm{~h}$. Images were taken at 0 and $24 \mathrm{~h}$. (B) Comparative chart of the healed area rates. Data are presented as the mean $\pm \mathrm{SD} ;{ }^{*} p<0.05,{ }^{* *} p<0.01$ compared with untreated cells. 
known that LTA is recognized by TLR2/TLR6, and activates NF- $\kappa B$ and/or MAPKs [11]. For example, aLTA isolated from $S$. aureus, sLTA isolated from L. sakei, and dLTA isolated from $L$. delbrueckii strongly induce TNF- $\alpha$ production $[3,12]$. pLTA isolated from L. plantarum, however, did not induce inflammatory responses, but instead inhibited proinflammatory cytokine production in cells stimulated by endotoxins [12]. Although every isoform of LTA is recognized by a common receptor, TLR2, the response of immune cells to different forms of LTA varies, due to the distinct structures of the isoforms. In this study, we examined the effect of aLTA on the regulation of adherens junction proteins in HaCaT cells. Previously, Kuo et al. [9] showed that PGN from $S$. aureus enhanced tight junctions, whereas LTA did not. In the current study, we also observed that aLTA only moderately induced or reduced tight junction-related protein expression (data not shown), whereas it significantly regulated adherens junction-related protein expression. When $\mathrm{HaCaT}$ cells were treated with $100 \mu \mathrm{g} / \mathrm{ml}$ aLTA, cell proliferation was reduced and EMT was induced. In the other study, we observed that CREB3L1 and VEGF levels were changed by aLTA and the cell population was significantly decreased after $48 \mathrm{~h}$ (data not shown). Moreover, $100 \mu \mathrm{g} / \mathrm{ml}$ aLTA also increased caspase activity and decreased the Bcl2 level, which led to cell apoptosis. Thus, a high dose of aLTA reduces $\mathrm{HaCaT}$ cell population through apoptosis, but survived cells then go to the EMT state. As we addressed in Figs. 2 and 3, E-cadherin and N-cadherin/Snail-1 are involved in the cell proliferation or wound healing and EMT of HaCaT cells. Wound healing and EMT might be regulated by signaling pathways, including ERK and NF- $\kappa$, which are differently regulated by a low and high dose of aLTA. The downregulation of E-cadherin and upregulation of N-cadherin and Snail-1 were observed in cells treated with a high dose of aLTA, which activated the ERK signaling pathway. Activation of ERK signaling has been shown to inhibit the degradation of Snail-1 in tumor cells [13]. When cells were given a low dose of aLTA, NF- $\kappa$ B was activated, leading to an increase in E-cadherin expression. In addition, a low dose of aLTA enhanced proliferation of HaCaT cells. On the other hand, a high dose of aLTA increased EMT. Although cell viability was decreased after $24 \mathrm{~h}$ of treatment with a high dose of aLTA, the surviving cells exhibited a mesenchymal phenotype, indicating that they had undergone EMT.

During the wound healing process, cell proliferation and reconstruction of the extracellular matrix are both increased to maintain cell and tissue structure. Thus, the effect of procollagen and matrix metalloproteinase (MMP) modulated by low-dose aLTA in keratinocytes should be addressed [14]. In the cells treated with a high dose of aLTA, EMT was induced, which may eventually promote the generation of tumors instead of wound healing. In future studies, the role of MMP expression, and cell invasion and migration caused by high doses of aLTA should be elucidated [15]. It is known that LTA induces EMT-mediated fibrosis through binding to TLRs [16]. In addition, because certain mutations in TLRs are known to induce tumor cell genesis, a study investigating the aLTA-TLR2-mediated signaling pathway would be useful to identify the underlying mechanisms of $S$. aureus infection and tumor cell genesis in keratinocytes $[17,18]$.

In this study, the interaction between HaCaT cells and aLTA was shown to vary in a dose-dependent manner. This suggests that the presence of $S$. aureus may induce either tumor cell genesis and EMT via adherens junction changes, or wound healing via immune activation in the infected region according to the population density of the bacteria. Monophosphoryl lipid A is a derivative of lipid A isolated from Salmonella minnestora R595 lipopolysaccharide [19, 20]. As a TLR4 agonist, it has been used as a vaccine adjuvant [21]. Similarly, aLTA could be considered as an agent to promote wound healing, although it should be modified to reduce toxicity against host cells.

\section{Acknowledgments}

This work was supported by a National Research Foundation of Korea (NRF) grant funded by the Korea government (MEST) (NRF-2016R1A2B1009889).

\section{References}

1. Li Z, Peres AG, Damian AC, Madrenas J. 2015. Immunomodulation and disease tolerance to Staphylococcus aureus. Pathogens 4: 793-815.

2. Tong SY, Davis JS, Eichenberger E, Holland TL, Fowler VG Jr. 2015. Staphylococcus aureus infections: epidemiology, pathophysiology, clinical manifestations, and management. Clin. Microbiol. Rev. 28: 603-661.

3. Jeong JH, Jang S, Jung BJ, Jang KS, Kim BG, Chung DK, et al. 2015. Differential immune-stimulatory effects of LTAs from different lactic acid bacteria via MAPK signaling pathway in RAW 264.7 cells. Immunobiology 220: 460-466.

4. Shiraishi T, Yokota S, Fukiya S, Yokota A. 2016. Structural diversity and biological significance of lipoteichoic acid in gram-positive bacteria: focusing on beneficial probiotic lactic acid bacteria. Biosci. Microbiota Food Health 35: 147-161.

5. Anderson JM. 2001. Molecular structure of tight junctions 
and their role in epithelial transport. News Physiol. Sci. 16: 126-130.

6. Kalluri R, Weinberg RA. 2009. The basics of epithelialmesenchymal transition. J. Clin. Invest. 119: 1420-1428.

7. Alistair JL, Warren T. 2002. How bacteria could cause cancer: one step at a time. Trends Microbiol. 10: 293-299.

8. Mager DL. 2006. Bacteria and cancer: cause, coincidence or cure? A review. J. Transl. Med. 4: 14.

9. Kuo IH, Carpenter-Mendini A, Yoshida T, McGirt LY, Ivanov AI, Barnes KC, et al. 2012. Activation of epidermal Toll-like receptor 2 enhances tight junction function: implications for atopic dermatitis and skin barrier repair. J. Invest. Dermatol. 133: 988-998.

10. Hattar K, Grandel U, Moeller A, Fink L, Iglhaut J, Hartung T, et al. 2006. Lipoteichoic acid (LTA) from Staphylococcus aureus stimulates human neutrophil cytokine release by a CD14dependent, Toll-like-receptor-independent mechanism: autocrine role of tumor necrosis factor-[alpha] in mediating LTAinduced interleukin-8 generation. Crit. Care Med. 34: 835-841.

11. McInturff JE, Modlin RL, Kim J. 2005. The role of Toll-like receptors in the pathogenesis and treatment of dermatological disease. J. Invest. Dermatol. 125: 1-8.

12. Kim HG, Kim NR, Gim MG, Lee JM, Lee SY, Ko MY, et al. 2008. Lipoteichoic acid isolated from Lactobacillus plantarum inhibits lipopolysaccharide-induced TNF-alpha production in THP-1 cells and endotoxin shock in mice. J. Immunol. 180: 2553-2561.

13. Yamaguchi H, Hsu JL, Hung MC. 2012. Regulation of ubiquitination-mediated protein degradation by survival kinases in cancer. Front. Oncol. 2: 15.
14. Volk SW, Iqbal SA, Bayat A. 2013. Interactions of the extracellular matrix and progenitor cells in cutaneous wound healing. Adv. Wound Care (New Rochelle) 2: 261-272.

15. Yadav L, Puri N, Rastogi V, Satpute P, Ahmad R, Kaur G. 2014. Matrix metalloproteinases and cancer - roles in threat and therapy. Asian Pac. J. Cancer Prev. 15: 1085-1091.

16. Kalluri R, Neilson EG. 2016. Epithelial-mesenchymal transition and its implications for fibrosis. J. Clin. Invest. 112: 1776-1784.

17. Khan AA, Khan Z, Warnakulasuriya S. 2016. Cancerassociated Toll-like receptor modulation and insinuation in infection susceptibility: association or coincidence? Ann. Oncol. 27: 984-997.

18. Perera M, Al-Hebshi NN, Speicher DJ, Perera I, Johnson NW. 2016. Emerging role of bacteria in oral carcinogenesis: a review with special reference to perio-pathogenic bacteria. $J$. Oral Microbiol. 8: 32762.

19. Qureshi N, Mascagni P, Ribi E, Takayama K. 1985. Monophosphoryl lipid A obtained from lipopolysaccharides of Salmonella minnesota R595. Purification of the dimethyl derivative by high performance liquid chromatography and complete structural determination. J. Biol. Chem. 260: 5271-5278.

20. Johnson DA, Keegan DS, Sowell CG, Livesay MT, Johnson CL, Taubner LM, et al. 1999. 3-O-Desacyl monophosphoryl lipid A derivatives: synthesis and immunostimulant activities. J. Med. Chem. 42: 4640-4649.

21. Poteet E, Lewis P, Li F, Zhang S, Gu J, Chen C, et al. 2015. A novel prime and boost regimen of HIV virus-like particles with TLR4 adjuvant MPLA induces Th1 oriented immune responses against HIV. PLoS One 10: e0136862. 